\title{
Simultaneous Determination of Phosphorus, Sulfur and Arsenic in Steel by Hydride Generation and Gas Chromatography
}

\author{
Tatsuhiko Tanaka*†, Yoshihiro Nakamura*, Atsushi Mizuike* and Akihiro Ono** \\ *Faculty of Engineering, Science University of Tokyo, \\ Kagurazaka, Shinjuku, Tokyo 162, Japan \\ **Advanced Materials \& Technology Research Laboratories, Nippon Steel Corporation, \\ Ida, Nakahara, Kawasaki, Kanagawa 211, Japan
}

\begin{abstract}
A sample was decomposed with boiling $6 \mathrm{M}$ hydrochloric acid in a helium stream in order to convert phosphorus, sulfur and arsenic into phosphine $\left(\mathrm{PH}_{3}\right)$, hydrogen sulfide and arsine $\left(\mathrm{AsH}_{3}\right)$, respectively, which were collected in a liquidnitrogen cold trap. The trap was warmed at $80^{\circ} \mathrm{C}$, and the three gases were then separated by gas chromatography on a Porapak QS column and detected with a photoionization detector. Phosphorus $(0.3-2.2 \mu \mathrm{g})$, sulfur $(0.8-3.5 \mu \mathrm{g})$ and arsenic $(4-4.5 \mu \mathrm{g})$ in steel were determined simultaneously with relative standard deviations of better than $7 \%(n=3$ to 4$)$ within $70 \mathrm{~min}$. The detection limits for phosphorus, sulfur and arsenic were 2, 280 and $4 \mathrm{ng}$, respectively.
\end{abstract}

Keywords Phosphorus, sulfur, arsenic, steel, hydride generation, gas chromatography

Recently, a simple and rapid method was developed in our laboratory for determining sulfur in steel, which consisted of sample decomposition in boiling $4 \mathrm{M}$ hydrochloric acid, a reaction of the evolved hydrogen sulfide with lead(II) acetate-impregnated paper tape and a reflectance measurement of the tape coloration. ${ }^{1,2}$ We have also tried a similar technique for determining phosphorus in steel. This has so far been unsuccessful because of interference from arsine ${ }^{3}$ in the detection of phosphine with silver nitrate-impregnated paper.

The present paper describes a simple method for simultaneously determining phosphorus, sulfur and arsenic at the $\mu \mathrm{g} \mathrm{g}^{-1}$ level in steel, in which the sample is decomposed with boiling hydrochloric acid in a helium stream, and the evolved phosphine, hydrogen sulfide and arsine are measured by gas chromatography using a photoionization detector (PID). The simultaneous determination of traces of phosphorus, sulfur and arsenic, which can affect the physical properties of steel, seems to be more desirable from the viewpoints of economy of time and labor. Phosphorus ${ }^{4}$, sulfur $^{5}$ and arsenic $^{6}$ in water samples were determined by using hydride generation with sodium tetrahydroborate, liquid-nitrogen cold trapping, and gas chromatography (GC) on a column of Chromosorb 102, Porapak QS or Tenax GC, with a photoionization or flame-photometric detector. However, the application to solid samples as well as a simultaneous determination of the three elements have not been reported in the literature.

† To whom correspondence should be addressed.

\section{Experimental}

\section{Apparatus}

The analytical system is shown in Fig. 1. A Pyrex reflux condenser and a $16 \mathrm{~cm} \times 6 \mathrm{~mm}$ i.d. Pyrex tube containing $2.5 \mathrm{~g}$ of magnesium perchlorate were added in order to remove hydrogen chloride and water. Part of the U-shaped Pyrex trap ( $5 \mathrm{~mm}$ i.d.) was loosely packed with quartz wool $(0.05 \mathrm{~g})$ for effectively collecting the evolved phosphine, hydrogen sulfide and arsine. For all connections, 2 or $4 \mathrm{~mm}$ i.d. PTFE tubes were used.

A Hitachi G-5000 gas chromatograph equipped with a helium-discharge photoionization detector was connected to a Hitachi D-2500 integrator. The column was prepared by packing a $3.25 \mathrm{~m} \times 2 \mathrm{~mm}$ i.d. coiledPTFE tube with Porapak QS (100 to 120 mesh) under suction and inserting quartz wool at both ends of the tube. It was preconditioned at $\mathrm{ca} .150^{\circ} \mathrm{C}$ for more than $48 \mathrm{~h}$, and reconditioned at $90^{\circ} \mathrm{C}$ for $30 \mathrm{~min}$ after each run.

\section{Reagents}

Reagent-grade hydrochloric acid was used without further purification. The purity of helium was $99.99 \%$. The standard gases used for calibration were phosphine $(11 \mathrm{ppm})$, hydrogen sulfide $(100 \mathrm{ppm})$ and arsine $(10 \mathrm{ppm})$ in nitrogen.

\section{Procedure}

Helium was introduced from inlet $A$ at a flow rate of $30 \mathrm{ml} \mathrm{min}^{-1}$ into the system. A weighed steel sample 


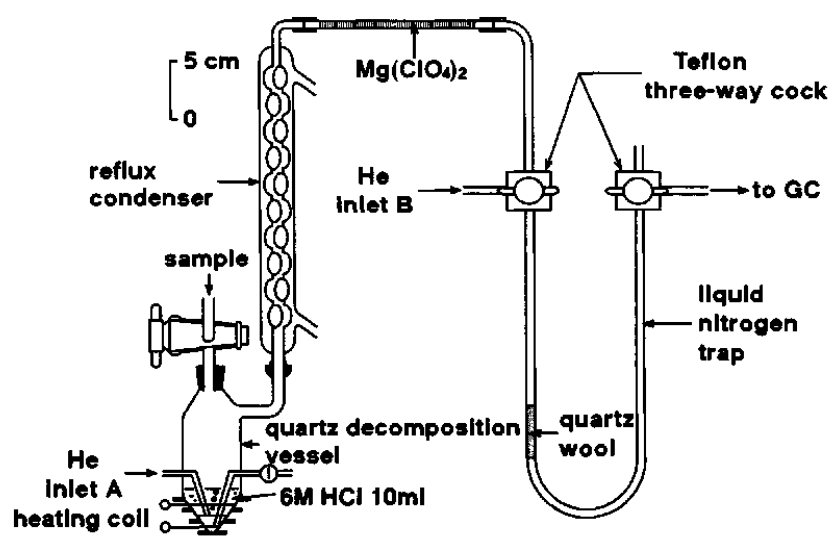

Fig. 1 Analytical system.

( $1 \mathrm{~mm}$ chips) was dropped into the decomposition vessel containing $10 \mathrm{ml}$ of $6 \mathrm{M}$ hydrochloric acid at $110^{\circ} \mathrm{C}$ and decomposed for 10 to $30 \mathrm{~min}$ to convert phosphorus, sulfur and arsenic into phosphine, hydrogen sulfide and arsine, respectively. The evolved gases were condensed in the liquid-nitrogen trap. The helium was passed for an additional $10 \mathrm{~min}$ after complete decomposition of the sample and discarded from the system. Then, helium was introduced from inlet $B$ at a flow rate of $40 \mathrm{ml} \mathrm{min}^{-1}$ into the trap. The condensed gases were then volatilized by replacing liquid nitrogen with hot water $\left(80^{\circ} \mathrm{C}\right)$ and introduced into the gas chromatograph.

\section{Results and Discussion}

\section{Chromatographic separation}

A PID (detector temperature, $100^{\circ} \mathrm{C}$; discharge gas flow rate, $50 \mathrm{ml} \mathrm{min}^{-1}$ ) was employed because of its sensitivity and wide measuring range for phosphine, hydrogen sulfide and arsine. ${ }^{5,6}$ Porapak QS was chosen as a chromatographic packing material from the viewpoint of its ability to separate hydrides from each other, and also interfering gases, which include aliphatic hydrocarbons (originating from carbon in steel), nitrogen (a diluent used for standard gases and contamination from the atmosphere) and water.

Prior to condensation of the hydrides, water and hydrogen chloride were removed as much as possible with the reflux condenser and the magnesium perchlorate tube. Water causes ice clogging in the cold trap and also interferes with the chromatographic separation of arsine. Magnesium perchlorate for organic elemental analysis (10 to $24 \mathrm{mesh}$ ) quantitatively passed traces of the desired hydrides; it was replaced after five runs. Anhydrous calcium chloride sorbed $c a .10 \%$ of phosphine.

Techniques were investigated for injecting the desired condensed gases onto the column. When the condensed gases were volatilized by placing the trap in ice water or in the ambient air, the split phosphine peak appeared at more than $1 \mu \mathrm{g}$ of phosphorus; also, the retention time

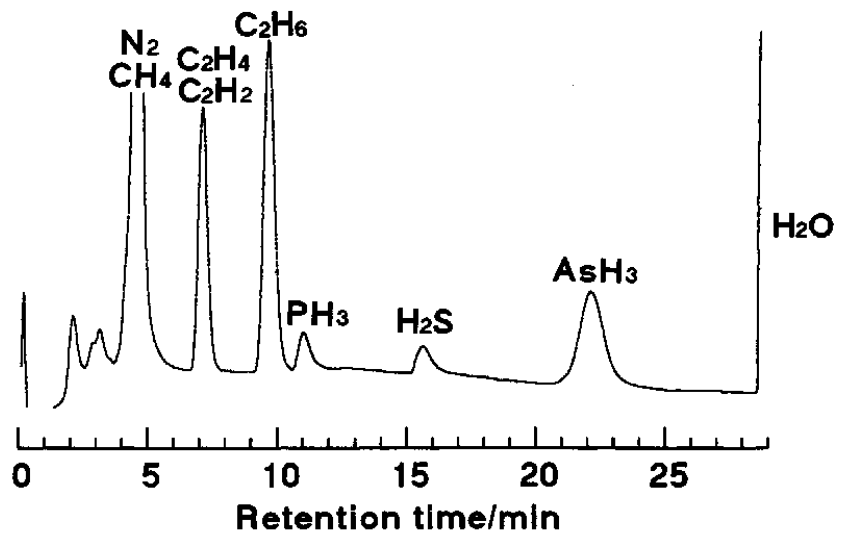

Fig. 2 Typical chromatogram (JSS 157-1, 0.05 g). Column, Porapak QS $3.25 \mathrm{~m}$; column temperature, $30^{\circ} \mathrm{C}$; carrier gas flow rate, $40 \mathrm{ml} \mathrm{min}^{-1}$.

was variable. Satisfactory peaks were obtained up to $2.5 \mu \mathrm{g}$ of phosphorus by immersing the trap in hot water $\left(80^{\circ} \mathrm{C}\right)$, which gave a more rapid temperature rise.

Figure 2 shows a typical chromatogram obtained by the proposed procedure. The methane peak overlapped with the nitrogen peak. The base line between the ethane peak and the phosphine peak was not established when the column temperature was higher than $30^{\circ} \mathrm{C}$ or the carrier gas flow rate was above $50 \mathrm{ml} \mathrm{min}^{-1}$. Although the best separation of phosphine was attained at a flow rate of $20 \mathrm{ml} \mathrm{min}^{-1}$, the retention time of arsine became longer than $30 \mathrm{~min}$. The optimum operating conditions from the standpoints of both complete resolution and a reasonable retention time were as follows: column length, $3.25 \mathrm{~m}$; column temperature, $30^{\circ} \mathrm{C}$; carrier gas flow rate, $40 \mathrm{ml} \mathrm{min}^{-1}$.

\section{Application to steel samples}

First, calibration curves were constructed by injecting the standard gases from inlet $\mathrm{A}$ into the system. Because the plots of the peak heights against the amounts of analytes were not linear, the peak areas were used as shown in Fig. 3. The curves for phosphorus $(0.2$ to $2.2 \mu \mathrm{g})$ and arsenic ( 1.8 to $3.3 \mu \mathrm{g}$ ) became straight lines and passed through the origin. The cause of the abnormality for less than $1.8 \mu \mathrm{g}$ of arsenic has not yet been clarified. This abnormality was quite reproducible: $\operatorname{RSDs} c a .5 \%(n=3$ to 5$)$. The curve for sulfur $(0.5$ to $3.5 \mu \mathrm{g})$ did not pass through the origin. Hydrogen sulfide was considerably reactive, and was slightly lost due to adsorption on the column, although the packing was silanized to minimize any adsorption loss. The adsorbed hydrogen sulfide was not eluted, even by raising the column temperature to $140^{\circ} \mathrm{C}$.

Table 1 summarizes the analytical results of several steel samples obtained by using calibration curves constructed with the standard gases (Fig. 3). The sampling weight was adjusted so as to keep the peak area within the linear range of the calibration curves. 


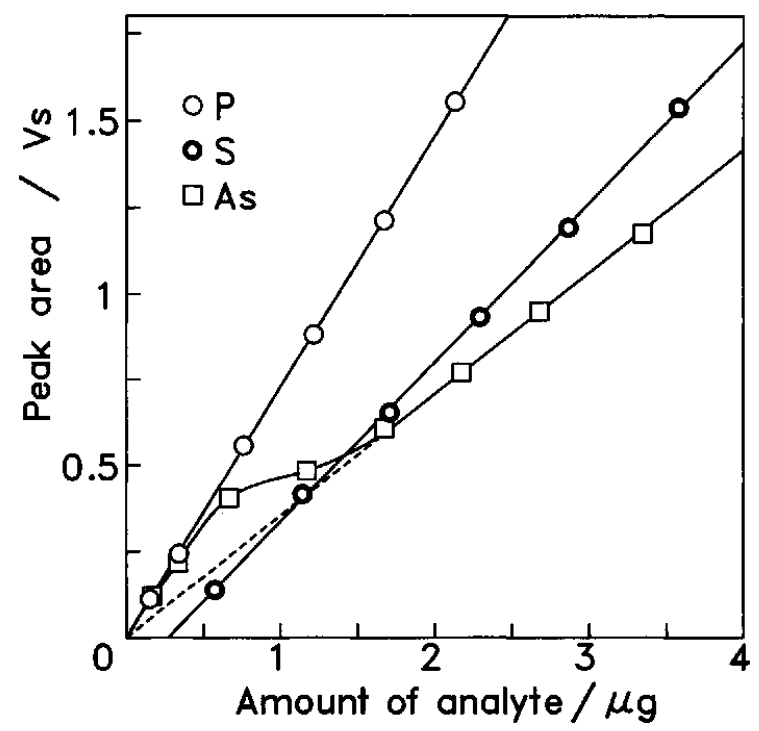

Fig. 3 Calibration curves constructed with standard gases.

Phosphorus in a JSS 066-1 high-carbon steel sample $(0.84 \% \mathrm{C})$ could not be determined because of incomplete resolution of phosphine and a large amount of ethane. The absolute detection limits $(3 \sigma)$ for phosphorus, sulfur and arsenic, evaluated by using 22 blank determinations, were 2, 280 and $4 \mathrm{ng}$, respectively. The time required for an analysis was within $70 \mathrm{~min}$. The obtained analytical values were lower than the certified values, indicating that phosphorus, sulfur and arsenic in steels were incompletely converted into phosphine, hydrogen sulfide and arsine in decomposition with boiling $6 \mathrm{M}$ hydro-

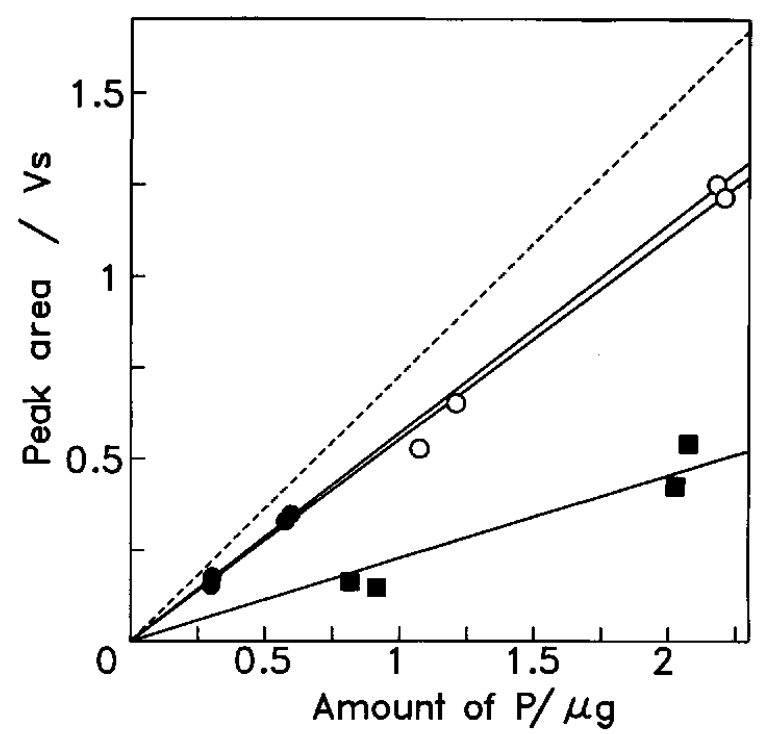

Fig. 4 Calibration curves of phosphorus constructed with JSS 002-2 (O), JSS 003-1 (O) and JSS 157-1 ( $\square$ ). The dashed line indicates a calibration curve constructed with standard phosphine gas.

chloric acid. The conversion yields depend greatly on kinds of steels, because the chemical state of the analytes in steels differs.

Figures $4-6$ show the calibration curves constructed with standard steel samples. For the same steel sample, the curves became straight lines and passed through the origin (except for sulfur). Consequently, calibration curves should be constructed with standard steel samples which are similar in chemical composition to the samples

Table 1 Analytical results of phosphorus, sulfur and arsenic in standard steel samples obtained by using the calibration curves prepared with standard gases

\begin{tabular}{|c|c|c|c|c|c|c|}
\hline Sample ${ }^{a}$ & Sample taken/g & $\begin{array}{c}\text { Certified value, } \\
\% \\
\end{array}$ & No. of detns. & $\begin{array}{c}\text { Found, } \\
\%\end{array}$ & $\begin{array}{c}\text { Conversion yield, } \\
\%\end{array}$ & $\begin{array}{c}\text { RSD, } \\
\%\end{array}$ \\
\hline JSS 002-2 & $0.15-0.3$ & $\begin{array}{c}\text { P: } \quad 0.0002 \\
\text { S: } \quad 0.0001^{b} \\
\text { As: }<0.0001\end{array}$ & 4 & $\begin{array}{c}0.00016 \\
\text { ND } \\
\text { ND }\end{array}$ & 80 & 2.9 \\
\hline JSS 003-1 & $0.1-0.3$ & $\begin{array}{rr}\text { P: } & 0.0011 \\
\text { S: } & 0.0004 \\
\text { As: } & <0.0001\end{array}$ & $\begin{array}{l}4 \\
4\end{array}$ & $\begin{array}{c}0.00083 \\
0.00030 \\
\text { ND }\end{array}$ & $\begin{array}{l}75 \\
75\end{array}$ & $\begin{array}{l}3.5 \\
1.9\end{array}$ \\
\hline JSS 066-1 & $0.015-0.03$ & $\begin{aligned} \text { P: } & 0.013 \\
\text { S: } & 0.011 \\
\text { As: } & 0.002^{b}\end{aligned}$ & 3 & $\begin{array}{c}-\overline{-} \\
0.0083 \\
\text { ND }\end{array}$ & 75 & 2.9 \\
\hline JSS $157-1$ & $0.02-0.05$ & $\begin{aligned} \text { P: } & 0.004 \\
\text { S: } & 0.006 \\
\text { As: } & 0.020\end{aligned}$ & $\begin{array}{l}4 \\
4 \\
4\end{array}$ & $\begin{array}{l}0.0011 \\
0.0025 \\
0.015\end{array}$ & $\begin{array}{l}28 \\
42 \\
75\end{array}$ & $\begin{array}{l}6.5 \\
6.3 \\
1.5\end{array}$ \\
\hline
\end{tabular}

ND: not detected. a. The Iron and Steel Institute of Japan standard steel samples. JSS 002-2: C, 0.0010\%; Si, 0.0008\%; Mn, 0.0003\%. JSS 003-1: C, 0.0011\%; Si, 0.0034\%; Mn, 0.0018\%. JSS 066-1: C, 0.84\%; Si, 0.26\%; Mn, $0.71 \%$. JSS $157-1: \mathrm{C}, 0.13 \% ; \mathrm{Si}, 0.32 \% ; \mathrm{Mn}, 0.47 \%$. b. These values were not certified and were given for information only. 


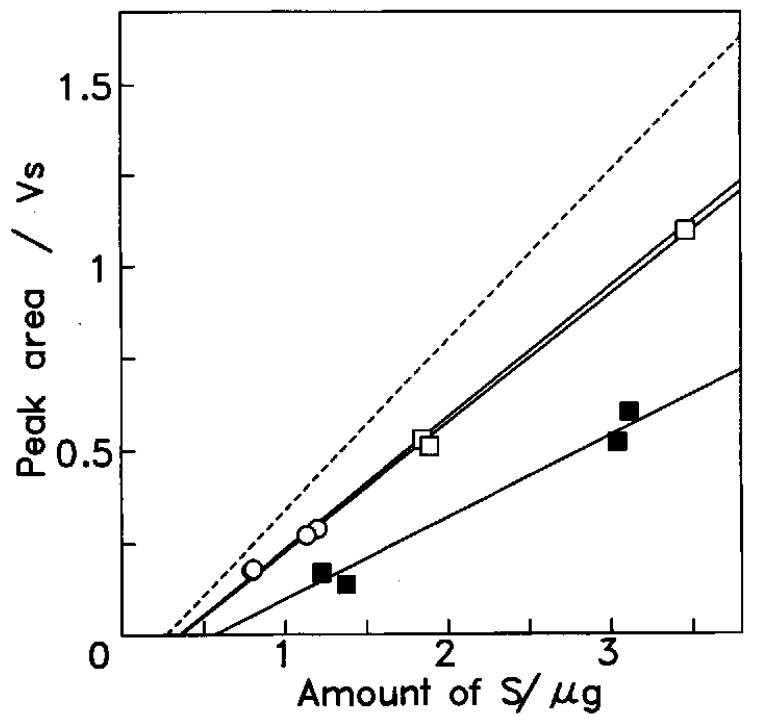

Fig. 5 Calibration curves of sulfur constructed with JSS 003-

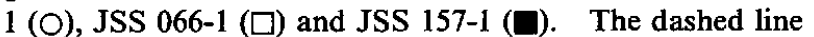
indicates a calibration curve constructed with standard hydrogen sulfide gas.

to be analyzed.

\section{References}

1. T. Tanaka, K. Kawahara, E. Tateo, A. Mizuike, Y. Hayakawa, A. Ono and M. Saeki, Anal. Sci, 8, 627 (1992).

2. T. Tanaka, E. Tateo, A. Mizuike, Y. Hayakawa, A. Ono and M. Saeki, Anal. Sci., 10, 667 (1994).

3. E. Tateo, K. Kawahara, T. Tanaka, A. Mizuike, Y.

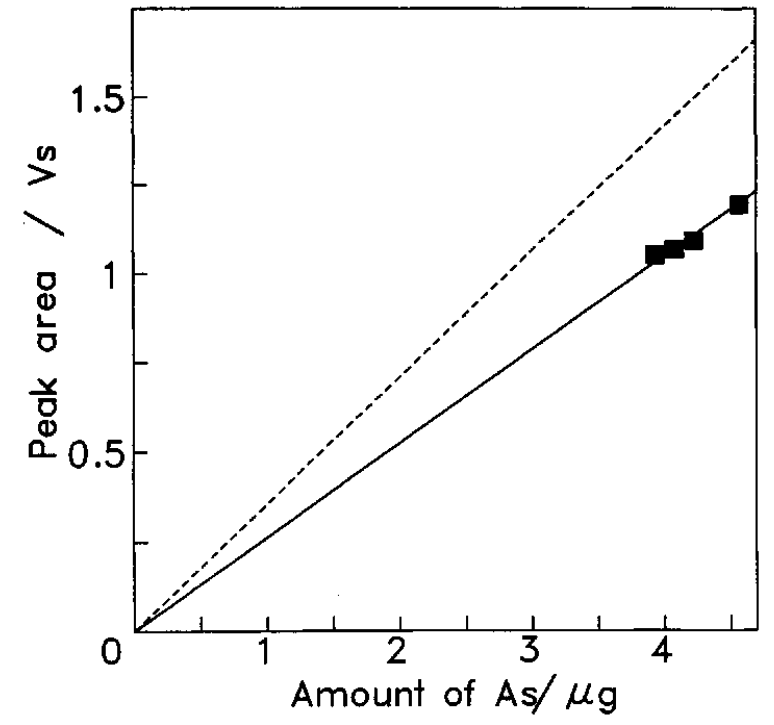

Fig. 6 Calibration curve of arsenic constructed with JSS 157-1 (ם). The dashed line indicates a calibration curve constructed with standard arsine gas.

Hayakawa, A. Ono and M. Saeki, Proceedings of the 41st Annual Meeting of the Japan Society for Analytical Chemistry, Kyoto, September, 1992, p. 48.

4. S. Hashimoto, K. Fujiwara and K. Fuwa, Anal. Chem., 57, 1305 (1985); Limnol. Oceanogr., 32, 729 (1987).

5. G. A. Cutter and T. J. Oatts, Anal. Chem., 59, 717 (1987).

6. S. H. Vien and R. C. Fry, Anal. Chem., 60, 465 (1988).

(Received October 3, 1995) (Accepted November 17, 1995) 